\title{
Double-layer Color Effects in Porcelain Systems
}

W. J. O'BRIEN, W. M. JOHNSTON, and F. FANIAN

University of Michigan, School of Dentistry, Department of Dental Materials, Ann Arbor, Michigan 48109-1078

The color of an unshaded body porcelain was determined at three thicknesses on white, gray, and three chromatic backings. Spectral absorption and scattering coefficients of the porcelain were determined from the diffuse reflectance at one thickness on the white and gray backings. These optical coefficients, when utilized with the Kubelka-Munk reflectance theory, accurately predicted the color of the other sample configurations studied. The scattering of the body porcelain was found to decrease with increasing wavelength within the visible spectrum, in accordance with scattering theory for particles not substantially less than the wavelength of the scattered light. For the filtering effects of a translucent material in optical contact with a backing, the Kubelka-Munk reflectance theory described the interaction between the optical absorption and scattering within the translucent material and the reflectance of the backing.

J Dent Res 64(6):940-943, June, 1985

\section{Introduction.}

The color of an opaque material is determined by the amount of visible light reflected to the observer from the illuminant (Hunter, 1975). The appearance of a porcelain restoration is mainly the result of the diffuse reflectance from a translucent layer covering an underlying opaque layer, as given in Fig. 1. A model for the diffuse reflectance of a translucent layer in optical contact with a backing is given by the Kubelka-Munk equation (Kubelka, 1948), as diagrammed in Fig. 2. The diffuse reflectance at a given wavelength, $R_{D}$, is given in terms of the reflectance of the opaque backing, $R_{G}$, the absorption coefficient, $K$, the scattering coefficient, $S$, and the thickness of the body porcelain, $X$. This form of the equation uses the hyperbolic cotangent function, ctgh, of the product of $S, X$, and a constant, $b$. This equation has been widely used to quantify the opacity of scattering materials (Judd and Wyszecki, 1975; Woolsey et al., 1984). The general theory of scattering of light by spherical particles of any size has been developed by Mie (1908).

In this study, the colors of layers of unshaded body porcelain on achromatic and chromatic backings were directly measured and then explained on the basis of the Kubelka-Munk theory and the applicable theory of the scattering of light in sintered materials.

\section{Materials and methods.}

Wet unshaded body porcelain ${ }^{1}$ was formed in a mold to a nearly oval shape, dried, and fired according to the manufacturer's directions. Using a slow-speed diamond blade saw, we made three slabs approximately $1,1.5$, and $2.5 \mathrm{~mm}$ thick. The faces of the samples were polished according to conventional metallographic polishing techniques. Reflectance samples were formed by joining each body porcelain

Received for publication September 17, 1984

Accepted for publication March 12, 1985

This research was supported by Grant DE-05423 from the National Institutes of Health, National Institu te of Dental Research, Bethesda, Maryland.

${ }^{1}$ Ceramco, Inc., East Windsor, NJ 08520 slab to each of five opaque modifier porcelain backings ${ }^{2}$ using a refractive index fluid $(n=1.5)$. The reflectance of each backing was determined by joining a clear microscope cover glass $(n=1.5)$ to each backing. The measured colors of the backings were white, yellow, pink, gray, and blue. The chromatic backings were made of dental modifier porcelains. The reflectance spectrum of each sample was determined twice in the visible range. The color of each reflectance sample and of each backing was determined using three color notations: (1) Commission Internationale

\footnotetext{
${ }^{2}$ Micro-Bond Natural Ceramic System, Austenal Dental, Inc.,
} Chicago, IL 60632

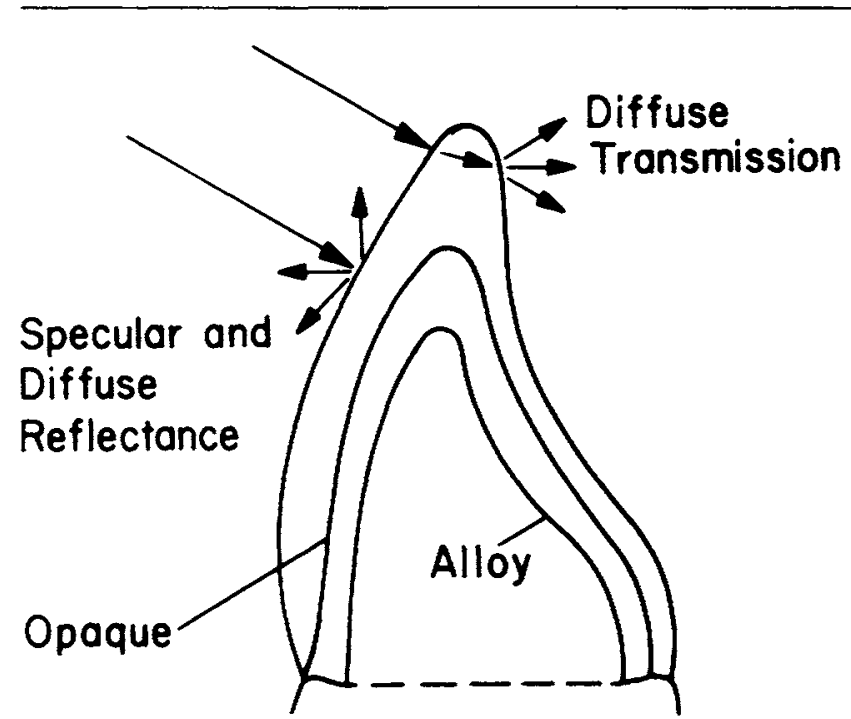

Fig. 1 - Reflection and transmission of light within a porcelainmetal restoration.

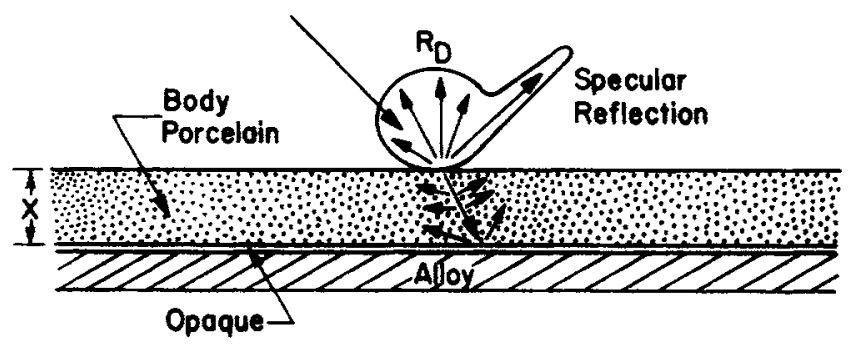

$$
\begin{aligned}
R_{D}= & \frac{1-R_{G}[a-b \operatorname{ctgh}(b S x)]}{a-R_{G}+b \operatorname{ctgh}(b S X)} \\
0 & =(K+S) / s \\
b & =\sqrt{a^{2}-1}
\end{aligned}
$$

Fig. 2 - The Kubelka-Munk theory applied to translucent body porcelain on an opaque backing. 
TABLE 1

CIE COLOR PARAMETERS FOR BODY PORCELAIN ON FIVE BACKINGS

\begin{tabular}{|c|c|c|c|c|}
\hline \multirow[b]{3}{*}{ Backing } & \multicolumn{3}{|c|}{ Luminous Reflectance (\%) } & \\
\hline & \multirow{2}{*}{$\begin{array}{l}\text { Clear } \\
\text { Glass }\end{array}$} & \multicolumn{3}{|c|}{ Thickness of Body Porcelain (mm) } \\
\hline & & 0.84 & 1.44 & 2.44 \\
\hline White & 81.1 & 64.7 & 53.6 & 42.5 \\
\hline Gray & 24.1 & 30.8 & 33.0 & $33.3^{\#}$ \\
\hline Blue & 19.5 & 29.0 & $\underline{31.8}$ & 33.1 \\
\hline Pink & 40.3 & 41.0 & 39.0 & 36.1 \\
\hline Yellow & 55.3 & 49.0 & 44.0 & 38.3 \\
\hline \multicolumn{5}{|c|}{ Dominant Wavelength $(\mathrm{nm})$} \\
\hline White & 559 & 553 & 543 & 501 \\
\hline Gray & 570 & 485 & 485 & 485 \\
\hline Blue & 472 & 475 & 476 & 480 \\
\hline Pink & $\underline{588}$ & 588 & 589 & 592 \\
\hline Yellow & $\underline{571}$ & 571 & 570 & 567 \\
\hline \multicolumn{5}{|c|}{ Excitation Purity (\%) } \\
\hline White & 1.6 & 1.3 & 0.9 & 0.7 \\
\hline Gray & 1.3 & 1.7 & $\underline{2.3}$ & 2.3 \\
\hline Blue & 31.7 & 15.7 & 10.1 & 5.6 \\
\hline Pink & 22.6 & 10.5 & 5.6 & 1.2 \\
\hline Yellow & 47.4 & 24.6 & 14.9 & 5.4 \\
\hline
\end{tabular}

\#The underlines connect values which are not statistically different. All other values for the same backing are significantly different.

de l'Eclairage (CIE), (1971); (2) Munsell (Newhall et al., 1943); and (3) Inter-Society Color Council - National Bureau of Standards (ISCC-NBS) (Kelley and Judd, 1976). Statistical differences between the CIE parameters were determined using Student-Newman-Keuls multiple comparison tests at a $95 \%$ level of confidence (Sokal and Rohlf, 1969).

At each measured wavelength, the average of the two measured reflectance values of the thinnest slab of the body porcelain on the white and gray backings was determined with a spectrophotometer ${ }^{3}$. The spectral optical absorption and scattering coefficients were determined, and surface reflection corrections were employed as previously described (Woolsey et al., 1984). The CIE color parameters of the other 13 observed conditions were predicted using the Kubelka-Munk theory. The Kubelka-Munk theory was then used to calculate the color of an infinitely thick layer of the body porcelain.

\section{Results.}

The average CIE color parameters are given in Table 1 for the measured samples. The two reflectance spectra measured at each condition were averaged, and the resultant Munsell color notations and ISCC-NBS color names are given in Table 2 .

The resultant optical scattering and absorption coefficients of the body porcelain are given in Fig. 3 . The agree-

\footnotetext{
${ }^{3}$ ACTA C-3 UV-visible Spectrophotometer, Beckman Instruments, Inc., Irvine, CA 92664
}

TABLE 2

MUNSELL COLOR NOTATION* AND ISCC-NBS COLOR NAME FOR BODY PORCELAIN ON FIVE BACKINGS

\begin{tabular}{|c|c|c|c|c|}
\hline \multirow[b]{2}{*}{ Backing } & \multirow{2}{*}{$\begin{array}{l}\text { Clear } \\
\text { Glass }\end{array}$} & \multicolumn{3}{|c|}{ Thickness of Body Porcelain (mm) } \\
\hline & & 0.84 & 1.44 & 2.44 \\
\hline \multirow[t]{2}{*}{ White } & $\begin{array}{l}8.5 \mathrm{GY} \\
9.1 / 0.3\end{array}$ & $\begin{array}{l}1.5 \mathrm{G} \\
8.3 / 0.3\end{array}$ & $\begin{array}{l}2.5 \mathrm{G} \\
7.7 / 0.3\end{array}$ & $\begin{array}{l}2.5 \mathrm{BG} \\
7.0 / 0.3\end{array}$ \\
\hline & White & Light Gray & Light Gray & Light Gray \\
\hline \multirow[t]{2}{*}{ Gray } & $\begin{array}{l}10.0 \mathrm{Y} \\
5.5 / 0.2\end{array}$ & $\begin{array}{l}8.5 \mathrm{~B} \\
6.1 / 0.3\end{array}$ & $\begin{array}{l}1.0 \mathrm{~PB} \\
6.2 / 0.6\end{array}$ & $\begin{array}{l}8.8 B \\
6.3 / 0.5\end{array}$ \\
\hline & $\begin{array}{l}\text { Medium } \\
\text { Gray }\end{array}$ & $\begin{array}{l}\text { Medium } \\
\text { Gray }\end{array}$ & $\begin{array}{l}\text { Bluish } \\
\text { Gray }\end{array}$ & $\begin{array}{l}\text { Bluish } \\
\text { Gray }\end{array}$ \\
\hline \multirow[t]{2}{*}{ Blue } & $\begin{array}{l}7.0 \mathrm{~PB} \\
5.0 / 6.4\end{array}$ & $\begin{array}{l}6.2 \mathrm{~PB} \\
5.9 / 4.0\end{array}$ & $\begin{array}{l}6.0 \mathrm{~PB} \\
6.2 / 2.5\end{array}$ & $\begin{array}{l}4.0 \mathrm{~PB} \\
6.3 / 1.4\end{array}$ \\
\hline & $\begin{array}{l}\text { Light } \\
\text { Purplish } \\
\text { Blue }\end{array}$ & $\begin{array}{l}\text { Pale } \\
\text { Purplish } \\
\text { Blue }\end{array}$ & Pale Blue & $\begin{array}{l}\text { Bluish } \\
\text { Gray }\end{array}$ \\
\hline \multirow[t]{2}{*}{ Pink } & $\begin{array}{l}3.5 \mathrm{YR} \\
6.8 / 3.5\end{array}$ & $\begin{array}{l}2.0 Y R \\
6.9 / 1.8\end{array}$ & $\begin{array}{l}1.9 Y R \\
6.7 / 0.9\end{array}$ & $\begin{array}{l}9.3 \mathrm{R} \\
6.5 / 0.3\end{array}$ \\
\hline & $\begin{array}{l}\text { Moderate } \\
\text { Yellowish } \\
\text { Pink }\end{array}$ & $\begin{array}{l}\text { Grayish } \\
\text { Yellowish } \\
\text { Pink }\end{array}$ & $\begin{array}{l}\text { Pinkish } \\
\text { Gray }\end{array}$ & $\begin{array}{l}\text { Medium } \\
\text { Gray }\end{array}$ \\
\hline \multirow[t]{2}{*}{ Yellow } & $\begin{array}{l}0.6 \mathrm{GY} \\
7.8 / 6.0\end{array}$ & $\begin{array}{l}1.0 \mathrm{GY} \\
7.4 / 3.0\end{array}$ & $\begin{array}{l}1.8 \mathrm{GY} \\
7.1 / 1.7\end{array}$ & $\begin{array}{l}4.8 \mathrm{GY} \\
6.7 / 0.7\end{array}$ \\
\hline & $\begin{array}{l}\text { Moderate } \\
\text { Greenish } \\
\text { Yellow }\end{array}$ & $\begin{array}{l}\text { Grayish } \\
\text { Yellow } \\
\text { Green }\end{array}$ & $\begin{array}{l}\text { Grayish } \\
\text { Yellow } \\
\text { Green }\end{array}$ & $\begin{array}{l}\text { Light } \\
\text { Greenish } \\
\text { Gray }\end{array}$ \\
\hline
\end{tabular}

${ }^{*} \mathrm{GY}$ is green-yellow, $\mathrm{G}$ is green, $\mathrm{BG}$ is blue-green, $\mathrm{PB}$ is purpleblue, $R$ is red, and YR is yellow-red.

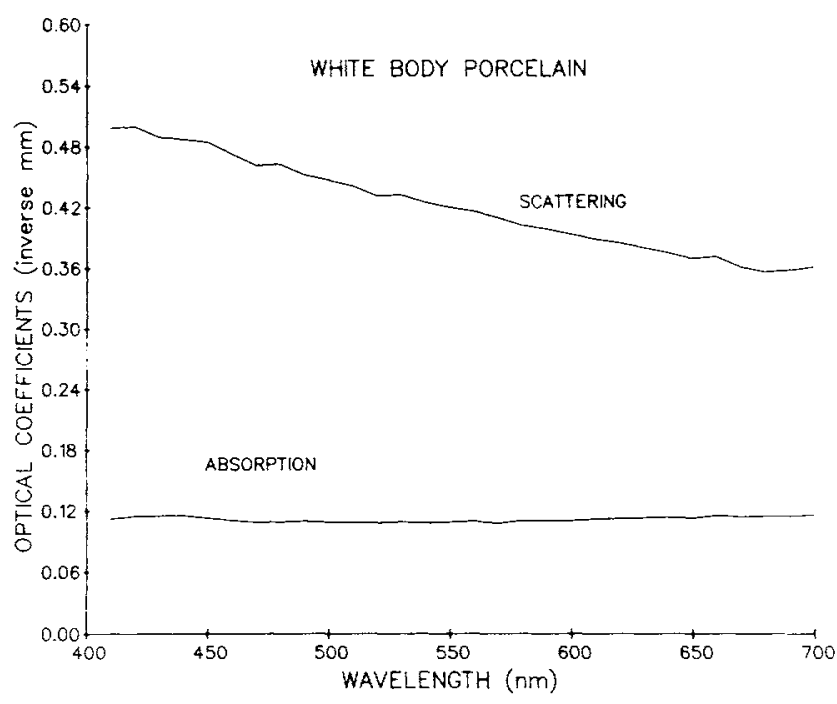

Fig. 3 - Spectral absorption and scattering coefficients of the body porcelain.

ment between the observed CIE color parameters and those predicted by the optical coefficients and Kubelka-Munk theory are given in Figs. 4-6.

Fig. 7 diagrams the change in reflectance predicted by the Kubelka-Munk theory for each of the five backings studied at the wavelength of $550 \mathrm{~nm}$. An infinitely thick layer of the body porcelain was calculated to have a lumi- 


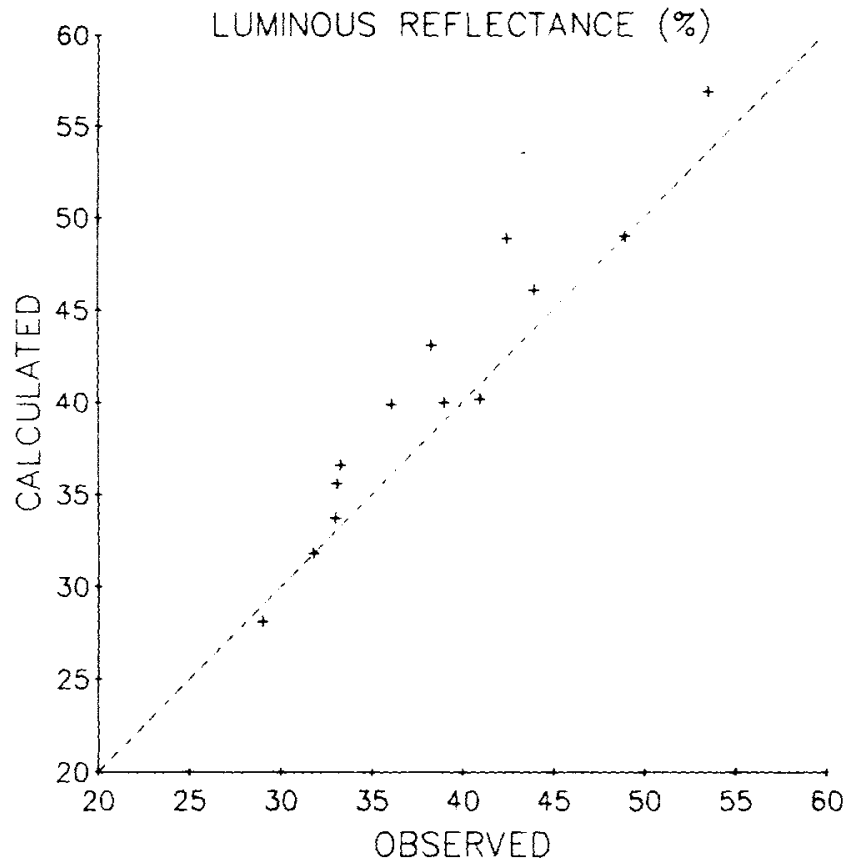

Fig. 4 - Agreement between the observed luminous reflectance and that predicted by the Kubelka-Munk theory.

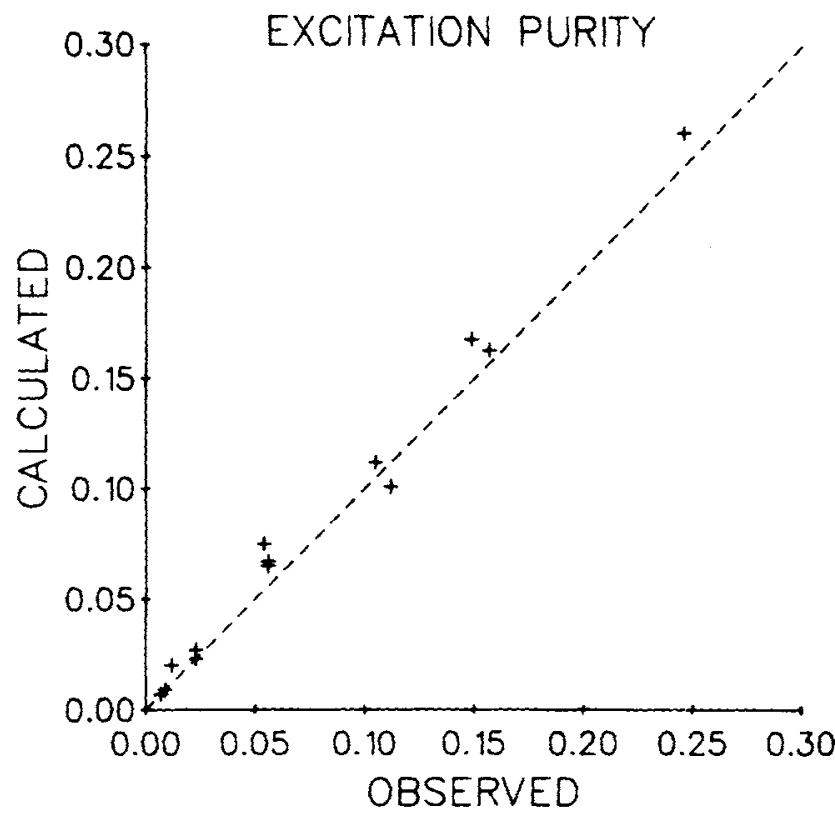

Fig. 5 - Agreement between the observed excitation purity and that predicted by the Kubelka-Munk theory.

nous reflectance of $39.7 \%$, a dominant wavelength of 486 $\mathrm{nm}$, and an excitation purity of $2.6 \%$.

\section{Discussion.}

Measurements of diffuse reflectance of a slab of translucent material on bright and dark backings may be used to calculate the optical scattering and absorption coefficients of the translucent material. These coefficients may then be used to calculate accurately the color of any thickness of that material on any backing. Good agreement was found

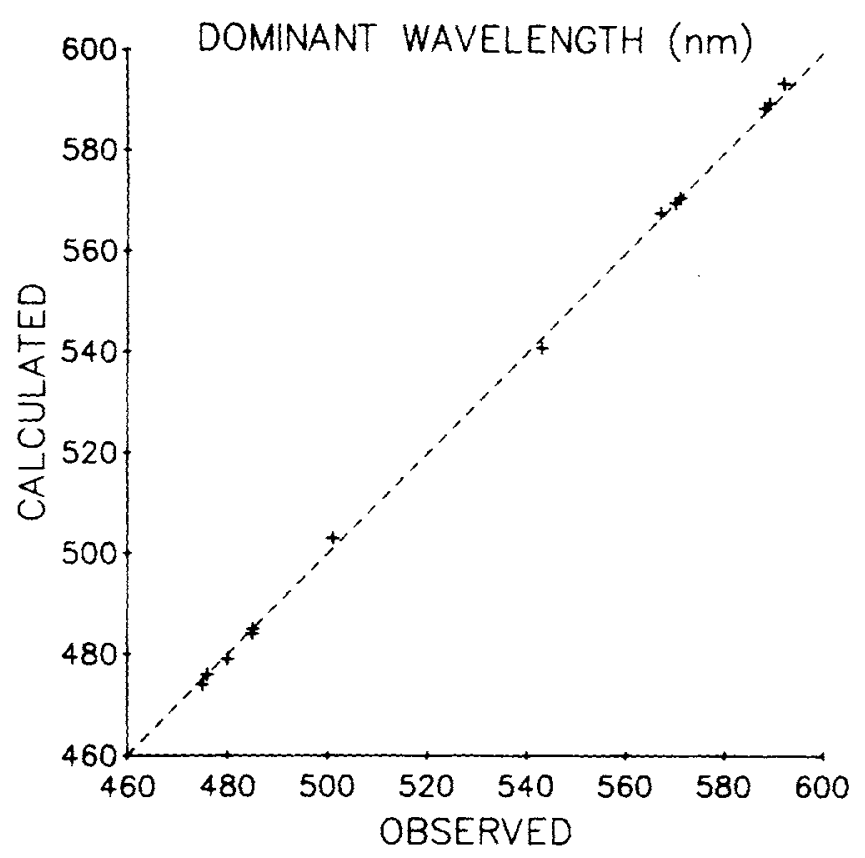

Fig. 6 - Agreement between the observed dominant wavelength and that predicted by the Kubelka-Munk theory.

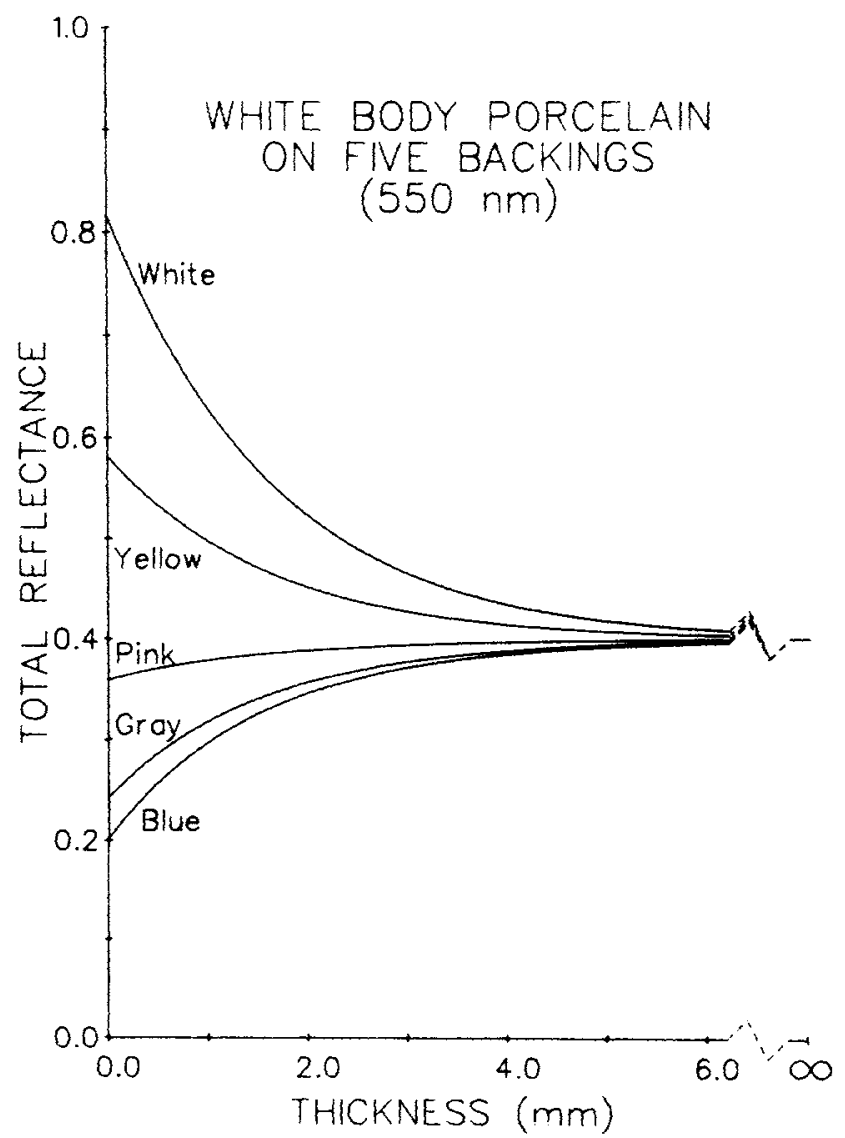

Fig. 7 - The reflectance of the body porcelain as a function of thickness at the wavelength of $550 \mathrm{~nm}$ for five backings. Each color name describes the backing for the respective curve.

between the experimental values and values calculated with the Kubelka-Munk equation as shown in Figs. 4-6. Therefore, once the values of $\mathrm{S}$ and $\mathrm{K}$ are obtained by reflectance measurements with the translucent porcelain on white and 
gray standards, the combined color of this porcelain on other colored substrates may be calculated.

The body porcelain studied has a scattering coefficient which is higher in the lower visible wavelengths. Increased scattering at lower wavelengths is described by Mie scattering theory for materials in which the scattering particles are not substantially smaller than the wavelength of the scattered light.

Although the color of an infinitely thick layer of the body porcelain is independent of any backing, the effects on color of increasing thickness of the body porcelain vary with the color of the backing. The changes in color parameters caused by the filtering effects of a translucent material over a backing result from the interaction, at every wavelength, of the optical scattering and absorption coefficients, the thickness of the translucent material, and the reflectance of the backing.

The practical application of the double-layer effect described by the Kubelka-Munk equation can be seen from examining Fig. 7. The diffuse reflectance of the white translucent layer over several colored opaque backings is shown as a function of porcelain thickness. As the thickness of the translucent porcelain over the light-colored backings (i.e., white, yellow) increases, the total reflectance decreases. These changes in total reflectance values are due to additive color mixing of the backing colors and that of the translucent porcelain. The total reflectance values increase as the thickness of the white porcelain increases to modify the color of the darker backings (i.e., pink, gray, and blue), since lighter combined colors are obtained. The thickness of the white porcelain necessary to screen out the color of the backing is seen to be around $6 \mathrm{~mm}$, which is called the infinite optical thickness. Since the average thickness of the translucent body porcelain layer of a crown is around $1 \mathrm{~mm}$, the total color is strongly influenced by the color of the opaque porcelain and highly sensitive to variations in body porcelain thickness. This effect is proposed as a major source of the poor color control of porcelain-fusedto-metal crowns in clinical practice. This double-layer effect is especially perplexing since the combined color formed is a complex function of the thickness of the body porcelain and not linear, as expected by many technicians and dentists.

\section{REFERENCES}

COMMISSION INTERNATIONALE de l'ECLAIRAGE (1971): Colorimetry, Official Recommendations of the International Commission on Illumination, Publication CIE No. 15 (E-1.3.1), Paris, France: Bureau Central de la CIE.

HUNTER, R.S. (1979): The Measurement of Appearance. New York, NY: John Wiley and Sons, pp. 18-57.

JUDD, D.B. and WYSZECKI, G. (1975): Color in Business, Science and Industry, 3rd ed., New York, NY: John Wiley \& Sons, pp. $420-438$.

KELLEY, K.L. and JUDD, D.B. (1976): Color: Universal Language and Dictionary of Color Names, Spec. Publ. 440. Washington, DC: Nat. Bur. of Stand. (U.S.), p. 10.

KUBELKA, P. (1948): New Contributions to the Optics of Intensely Light-scattering Materials. Part I, J Opt Soc 38:448-457.

MIE, G. (1908): Beitrage zur Optic truber Median, speziell kolloider Metallosungen, Ann Physik 25:377-445.

NEWHALL, S.M.; NICKERSON, D.; and JUDD, D.B.: Final Report of the O.S.A. Subcommittee on the Spacing of the Munsell Colors, JOpt Soc Am 33:385-418.

SOKAL, R.R. and ROHLF, F.J. (1969): Biometry, San Francisco, CA: W.H. Freeman and Co., pp. 239-246.

WOOLSEY, G.D.; JOHNSTON, W.M.; and O'BRIEN, W.J. (1984): Masking Power of Dental Opaque Porcelains, $J$ Dent Res 63:936939. 